\title{
Post-Hurricane Schooling in Puerto Rico and the Virgin Islands and an Adapted Hierarchy of Needs
}

\author{
James Lane \\ University of Phoenix \\ Shaquanah Robinson \\ University of Phoenix
}

\author{
Alyncia Bowen \\ Franklin University
}

Denise Rattigan

Aurora University

\section{Belinda Moses}

Wayne County Community College

We applied narrative inquiry to describe, understand, and gain insight into the significant experiences of educators and graduated students in the U.S. Virgin Islands and Puerto Rico as they attempted to reengage in formal schooling following the effects of two devastating hurricanes in September 2017. We viewed participant responses through a conceptual framework that melded the ethics of critique, justice, care described by Starratt with an adaptation of Maslow's hierarchy of needs. Our findings suggest insights into ways that educators apply personal and professional values as they attempt to resume schooling in the aftermath of personal and community disasters.

Keywords: educator ethics, narrative, Maslow, hurricanes, Virgin Islands, Puerto Rico

\section{INTRODUCTION}

Hurricanes Irma and Maria wreaked tragedies in September 2017 when the category 5 storms ravaged the Virgin Islands and Puerto Rico. Winds averaged as high as $185 \mathrm{mph}$, and gusts reached $215 \mathrm{mph}$. The result was a sudden and stark transformation "from paradise to post-nuclear," leaving residents without power for months (Bram, 2018; Dwyer, 2017; Peters, 2017).

Residents faced fundamental challenges of physical and economic survival that significantly compromised community institutions, including the education system (Bram, 2018). Students lost valuable instruction, and educators balanced their own personal needs against those of their students and community. This narrative study captured the perceptions of educators and adult graduated former 
students as they experienced schooling after the storms. Much information exists describing the extent of the physical damage and economic impact of these storms. Little information exists, however, describing the experiences of educators and students engaged in schooling following the storms.

\section{PURPOSE}

The purpose of this narrative study was to understand the perceptions of educators and students in Puerto Rico and the U.S. Virgin Islands as they re-engaged in schooling after the effects of two devastating hurricanes in September 2017. This study indicates processes through which individuals, communities, businesses, government agencies, and schools interacted following the overwhelming devastation in order to resume their roles as educators and students. The study reflects personal insights the participants gained through their experiences.

\section{RESEARCH QUESTIONS}

Through this study we sought to answer the following research questions:

RQ1: What significant challenges did students and educators in Puerto Rico and the Virgin Islands face after experiencing widespread devastation wrought by Hurricanes Irma and Maria in September 2017?

RQ2: How did participants apply personal and professional ethics during the aftermath of these hurricanes?

RQ3: What was it like to experience and re-engage in formal educational practices and learning following the storms?

\section{CONCEPTUAL FRAMEWORK}

This section explains our conceptual journey as we worked to capture, describe, and understand what it was like to experience schooling during the traumatic aftermath of hurricane desolation in Puerto Rico and the Virgin Islands in September 2017. We began our study by viewing our participants' responses through a conceptual framework that melded the ethics of critique, justice, care (Starratt, 2012), and the ethic of community (Furman, 2004) with turbulence theory (Shapiro \& Gross, 2013). The ethic of critique deals with questions of social justice and human dignity. The ethic of justice is connected with legal or codified procedures. The ethic of care focuses on personal relationships. The ethic of community is the "moral responsibility to engage in communal processes as educators pursue the moral purposes of their work and address the ongoing challenges of daily life and work in schools" (Furman, 2004, p. 215). The premise of turbulence theory posed by Shapiro and Gross (2013) is that in times of extreme turbulence, in this case a natural disaster, educators apply one or more of these ethics in response to specific crises.

As we analyzed our data, however, we realized that the application of Turbulence Theory as defined by Shapiro and Gross (2013) did not capture the depth of the physical and emotional trauma our educators and students experienced during and after the storms. The authors explain that the theory "transcends the need to describe these sudden and sometimes wrenching changes; it is meant to help us gain perspective" (2013, p.57). While we agree that gaining broader perspective regarding cataclysmic events is vital, that was not the purpose of our study.

We then turned to Maslow's concept of a hierarchy of needs as a more appropriate prism through which to view these catastrophic experiences. We are not professional psychologists, and we do not present ourselves as experts on A.H. Maslow and his thoughts. Rather, we identified Maslow's hierarchy as a frame commonly used in ethnography through which to view ways that humans strive to overcome emotional trauma. As we worked to understand our data, we adapted the hierarchy in a way that we believe is suited to this study. 
As we worked, we found that ideas of Bandura complemented our adaptation of Maslow's hierarchy. Bandura (1971) posited that "new patterns of behavior can be acquired through direct experience or observing the behavior of others" (p.3). Bandura believed that people continually face situations in which they have to decide how to deal with those situations. We see our participants as continually interacting with their environment and those around them in order to overcome remarkable hardships. We believe these interactions are represented in the themes displayed in our revised hierarchy.

Maslow (1962; Bridgman, Cummings, \& Ballard, 2019) includes at his hierarchy's first two levels Physiological Needs: Air, water, food, shelter, sleep, clothing, reproduction; and Safety Needs: Personal security, employment, resources, health, property. We titled our base as Turbulence, Destruction, and Physiological Needs. We placed Psychological and Safety Needs as our second tier. At Level 3 Maslow lists Love and Belonging: Friendship, intimacy, family, sense of connection. We agree with the importance of those concepts but saw them as more applicable in Level 4 . We labeled our Level 3 as Resilience, which we saw emerge as a strong theme. Maslow lists Level 4 as Esteem: Respect, selfesteem, status, recognition, strength, freedom. We found those themes more relevant for our Level 5 . We identified our Level 4 as Care, Love, Community, and Belonging. At Level 5 Maslow places SelfActualization: Desire to become the most that one can be. We don't presume to know whether our participants reached any points of self-actualization, although several did express epiphanies of love, community, and self-reliance. Thus, at the top of our framework we placed Esteem, Self-Respect, and Freedom, concepts that we saw both as strong themes and consistent with Maslow's thinking. Our hope is that we have captured a visualization to explain their perceptions. Our framework is visible as Figure 1 below.

\section{FIGURE 1 \\ ADAPTED HIERARCHY OF NEEDS AND CONCEPTUAL FRAME}

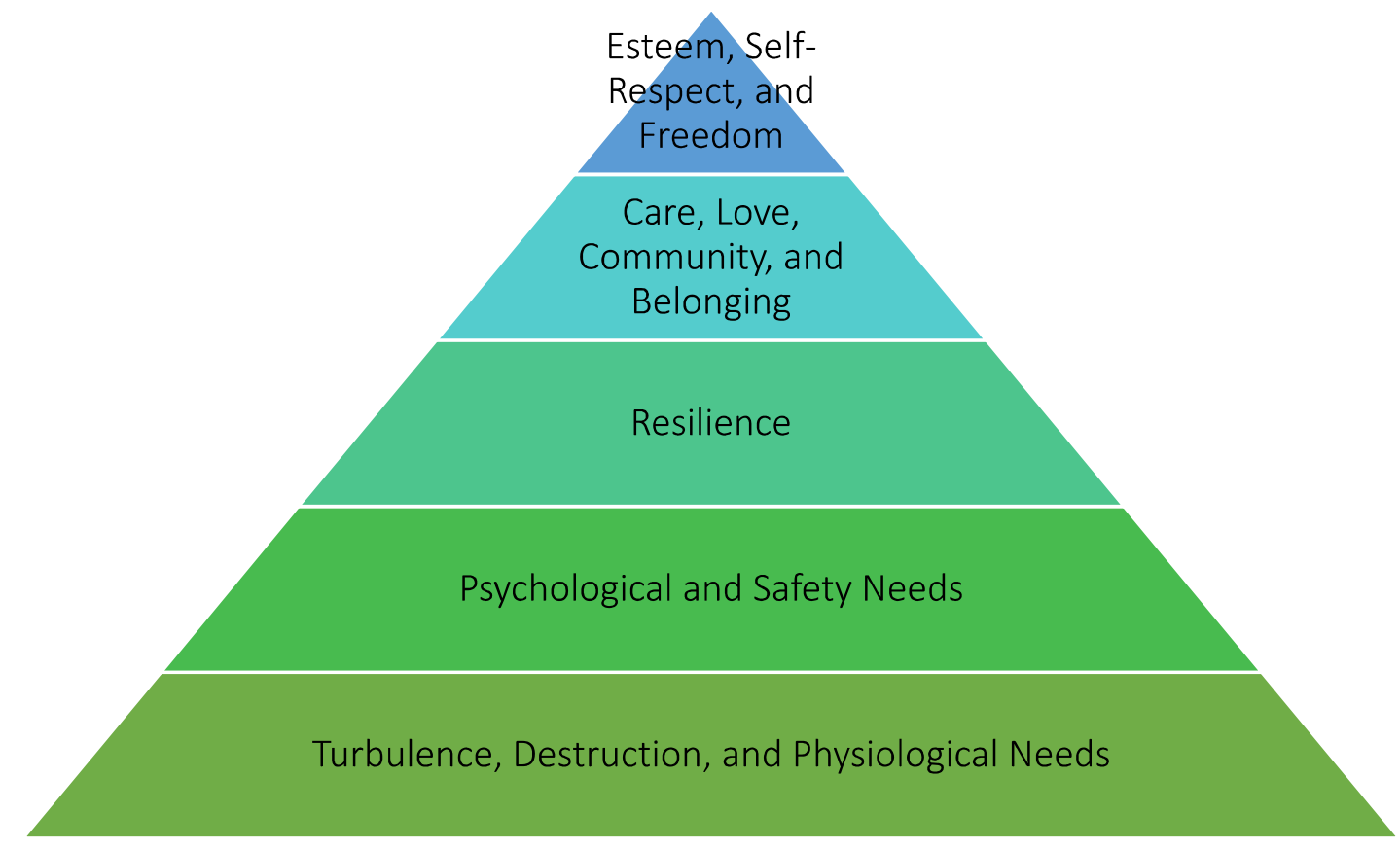

\section{LITERATURE REVIEW}

Our purpose in conducting this study was to capture the significant experiences of participants following the storms. We do not distinguish between the specific destructive effects of the two hurricanes, 
nor do we provide guidelines for storm preparation or recovery. We provide general factual information describing the impacts of the storms as background for our participants' descriptions.

Hurricanes Irma and Maria ransacked Puerto Rico and the U.S. Virgin Islands (USVI) twelve days apart in September 2017. Irma attacked first on September 8. With winds surpassing $185 \mathrm{mph}$, it became the strongest Atlantic Ocean hurricane ever measured. Irma targeted St. Thomas and St. John of the USVI, as well as portions of eastern Puerto Rico, impacting over one million people (U.S. Department of Agriculture, 2017). Hurricane Maria followed twelve days later on September 19-20, bringing devastation again to Puerto Rico and to St. Croix, USVI. The category 5 storms caused destruction to infrastructure, housing and the economy. In both Puerto Rico and the Virgin Islands, many residents remained without power and running water for months (Bram, 2018; Dwyer, 2017; Perez-Pena, 2017; Raphelson, 2017). It took weeks for the residents to acquire potable water or electricity, with $95 \%$ of the islands without power.

Physical damage of approximately $\$ 759.4$ million was attributed to the hurricanes in Puerto Rico. Electricity was lost in approximately 1.1 of the 1.5 million homes on the island during Hurricane Irma. Maria completely destroyed the power grid of the island, leaving all the 3.5 million residences without electricity (The New York Times, 2017). Death counts in Puerto Rico approached 3,000 (Milken Institute School of Public Health, 2018). In Puerto Rico, the storms wreaked widespread damage to homes, infrastructure, and agriculture, with $80 \%$ of crops destroyed (Bram, 2018). Up to 362,000 customers lost water services. Many roads were blocked by fallen trees (Storm Events Database, 2017). Economically, $25 \%$ to $30 \%$ of the coffee, banana, plantain, and papaya crops were damaged. The loss to farmers was estimated at \$30.6 million (Alvardo, 2017).

The official count of five deaths in the Virgin Islands was much lower than that in Puerto Rico (Bram, 2018). Nonetheless, physical devastation was widespread. Within the telecommunications industry, 781 out of 1,600 telecommunication towers were incapacitated (U.S. Virgin Islands Department of Education, 2018). The damage to the telecommunications infrastructure caused $90 \%$ of the islanders to lose internet access (U.S. Virgin Islands Department of Education, 2018). Over 85\% of the households reported damage to their homes, and total damages were estimated at more than $\$ 10.6$ billion. (U.S. Virgin Islands Department of Education, 2018). Almost all schools received some damage. Many were significantly damaged or destroyed, with costs estimated at $\$ 676$ million (U.S. Virgin Islands Department of Education, 2018).

In addition to physical damages were the emotional and psychological turmoil wrought upon the inhabitants. These effects have been identified as symptomatic of Post-Traumatic Stress Disorder (PTSD) (Martin, 2019; Koh, 2019). Scholars have discussed similar effects following other natural disasters (Chen, et al., 2014; Lucario, 2018; Reifels, et al., 2013; Yawson, et al, 2015). The most comparable natural disaster on the U.S. mainland was Hurricane Katrina. That storm killed more than 1,000 people, uprooted more than 500,000, and caused more than $\$ 100$ billion in damages (Galea, et al., 2007). The significant psychological and emotional effects of Hurricane Katrina on its victims have been documented (Madrid \& Grant, 2007; Galea, et al., 2007). As we noted above, we are not psychologists, and we do not present this as a psychological study. Our participants did report psychological trauma consistent with these broader discussions, however, and so we describe those in this study. We have found no studies describing the perceptions of educators and former students following these or other natural disasters. Thus, we believe our study presents a new contribution to the field.

\section{METHOD AND DESIGN}

We applied narrative inquiry as a method to capture and reconstruct participants' "significant formative experiences" (Bruner, 2002, p. x) by tapping into their "continuing interpretation and reinterpretation of their experience" (Bruner, 1987, p. 12). Riesman notes that narrative inquiry is "grounded in the study of the particular . . how and why incidents are storied, not simply the content to which language refers" (2008, p. 11). Clandinin and Connelly define narrative inquiry as "trying to make sense of life as lived" (2000, p. 78). Lawrence-Lightfoot stresses that narratives must be depicted in 
context. She explains, "By context, I mean the setting - physical, geographic, temporal, historical, cultural, aesthetic - within which the action takes place . . . It is used to place people and action in time and space and as a resource for understanding what they do" (1997, p. 41). We believe narrative inquiry was the most appropriate method to understand the perceptions of our participants

Our population was comprised of educators and students in Puerto Rico and the U.S. Virgin Islands who experienced Hurricanes Irma and Maria in September 2017. We selected our sample population through a process of purposive and snowball sampling (Saldana \& Omasta, 2018; Meriam \& Tisdell, 2015; Creswell, 2013). Our data are gleaned from the reflections of six participants. We had envisioned a broader response, but experienced unexpected difficulties in securing participants. Four of the five members of our research team knew personally or professionally one or more people who met our target criteria. Those contacts assured us that not only would they speak to us, but that they would be able to enlist others to participate. Among several specific commitments, some stopped returning emails. Other promised snowball contacts did not materialize. Although we can surmise that these experiences may have been too traumatic to for these prospective interviewees to discuss, or that perhaps they were too busy rebuilding their lives, we do not know why these obstacles occurred.

Despite these setbacks, we are pleased that our small sample represents private and public schools, elementary and secondary teachers, one former high school student and one graduate school student from an online university. Two of our participants were based in Puerto Rico and four were based in St. Croix. Geography, however, did not seem to make any differences in the types of responses we received. That is, responses were consistent across interview questions and themes. For that reason, we have not disaggregated our participants according to their geographic base. Another consistent point made by our participants was that they saw themselves collectively as a unique amalgamation of races and religions. With that, we decided not to collect ethnicity data from participants, due to the diverse and mixed ethnicities of Islanders. For that reason, we have not identified individual ethnicities and we apply the word "Islanders" as a proper noun. We understand that our small sample limits the scope of our study. We are encouraged, however, that the themes we represent here strongly resonated throughout our data. Here is a brief description of the roles of our participants. Julia was a K-6 art teacher working in a private school. Sandra was a K-6 teacher working in a Montessori school. Dorsett was a high school art teacher. Jossette was a high school teacher of students with learning disabilities. John was an online graduate student who worked for the federal government. Joseph was a high school senior.

In a process described by Saldana and Omasta (2018), we used our ethical frames to filter our participants' responses. Following Saldana's model (2016), we first recorded and transcribed each interview and separate units of discourse into groups of one to three sentences. We then color-coded elements that first reflected one of the five levels of Maslow's Hierarchy of Needs that we modified for this study. In addition, however, we highlighted those words or phrases that seemed unique or, per Saldana, to "stand out" (2016, p. 13). We read the coded transcripts separately and then together in order to establish interrater reliability. In addition, as we read and coded, we recorded thoughts and insights in what Saldana calls "analytic memos" (2016, p. 21) for future reference. We met often to discuss our interpretations of the data moved through several iterations of understanding. Through several recursive iterations of reading, coding, and reflecting, both individually and collectively, we developed our insights and themes. Those are represented in our modified hierarchy of needs, explained through the musings of Bandura (1971) and infused with the ethics of critique, justice, care (Starratt, 2012) and community (Furman, 2004).

As is obvious, we also chose to use first person plural case as our writing style. We believe this approach best represents narrative inquiry and is helps create a sense of fluency as we represent both direct and indirect quotations from our data. We have also used active verbs to describe the destruction wrought by the hurricanes. While we do not intend to anthropomorphize the storms, we believe such word choice helps us best capture the thick description (Richardson, 2003) necessary to explain such devastation. 


\section{RESULTS}

The categories of our framework also served as our key themes. We identified our first tier and theme as Turbulence, Destruction, and Physiological Needs. Participants told poignant stories of their roofs blown off and their homes filled with water. Some were without electricity for months. They told stories of waiting in long lines to buy gas and groceries from vendors who would only take cash. They told of dark classrooms with no electricity and of students unable to focus on their studies as sweat dripped off their noses in 100-degree heat. When schools did open, they did so with limited hours. Several told of early curfews, which limited the times they could be on roads. In one high school, the football field was converted to temporary housing, holding multiple rows of manufactured homes.

Sandra remembered, "Water was about $2 \frac{1}{2}$ feet deep in our home. Our ceiling caved in." Julia recalled, "Most of the school had flood damage, landscaping damage, and there was a hole in the roof. The windows were blown out of some of the classrooms. Sometimes breezes came through the window. It was very hot. Some parts of the island did not get electricity until after Christmas. The first two weeks after the storm, no one was able to leave his or her homes." She explained, "Nothing could be bought without cash: ice, generators, gas, food, etc. We were paying $\$ 10$ for a bag of ice." John observed, "We became cave men in the $21^{\text {st }}$ century." Jossette remembered, "I knew I didn't have a home to go back to. I said, "What am I going to do?" Joseph, the high school student, best captured the surrealistic experience: "I felt like the world was ending. Everything was dead. The sky was gray. The land was brown. It was like Armageddon."

We identified our second tier and theme as Psychological and Safety Needs. Participants told of pothole-filled single-lane roads that lengthen normally brief school commutes to 90 minutes. They spoke of mental and physical exhaustion. Students told of the trauma of missing college and financial aid deadlines. Teachers also spoke of their classrooms as havens of refuge as the students returned to school. They altered their curricula to meet the needs of their traumatized students. Julia noted, "My way of coping was adjusting my curriculum. I decided school needed to be a refuge for them. I would try to get them back in a calm place. I taught them embroidery. They loved it! They learned to do things with their hands, which is what they needed." Juanita, remembered, "I would have children who would come in and cry or be angry. I would try to get them back to a calm place."

Several talked of depression and fear of new storms. Dorsett recalled, "It was a horrible night of noise and terror. It felt like a bomb or something went off." Juanita shared, "Every time it rains, I get nervous because I don't know what is going to come with the rain. I am afraid of the hurricane and afraid when the hurricane is coming. Many people began showing signs of PTSD if there was a drizzle of rain. I know some people now really get freaked out by wind and rain."

We identified our third tier and theme as Resilience. This theme permeated through each story. Our participants identified as independent islanders. We interpreted these as elements of Legal and Social Justice and embedded these references within this theme. Reports of government help were consistent but mixed. While our participants appreciated any outside help they received, they banded with their friends and families to overcome their hardships. Sandra recalled, "Neighbors pulled together and helped one another out of a rut and even helped each other survive." She observed, "I'm not an urban person who needs all the luxuries of life. I'm a rough tough cream puff. Someone said I would make a good pioneer woman. That's the way people are here." John, summarized, "As islanders, we hoped for support, but in reality, we had to have our own back. We were hoping or supposed to get aid and support, but we could not rely on it. We pulled ourselves up by our bootstraps and did what we had to do."

Justice was reflected inversely in our participants' beliefs that they were denied benefits and attention accorded to mainland U.S. citizens. Critique was reflected in their sense of being recipients of discrimination as Islanders. Joseph spoke for his peers as he recalled the frustration of trying to complete important pre-college tasks, such as completing college applications and applying for financial aid. "People got denied to colleges because of post-hurricane situations. We had to do college applications in a few days. People missed deadlines. (One college) wanted to interview me, but I couldn't for two weeks because of no Internet, so they dropped my application." He also explained the frustration of taking 
Advanced Placement exams after experiencing such significant disruptions. "If your house was destroyed, it was hard to concentrate."

Juanita remembered, "Hundreds of people died as a result of having to leave-especially the elderly. The information that the news outlets shared in regards to few deaths was a big lie. It was disheartening to know how we were dismissed and not recognized as being a part of the United States." Dorsett observed, "There is a real divide between the wealthy and working people." John reflected, "Puerto Rico and the Virgin Islands are in colonial mentality - we have to do $150 \%$."

We identified our fourth tier and theme as Care, Love, Community, and Belonging, which also emerged quickly as a strong motif. We were especially moved by teachers' stories making their classrooms safe harbors for their students who were often crying and angry. Elements of community and belonging spoke loudly through the data as participants told of joining together to clean and repair homes, roads, and schools. Care was a dominant theme reflected in their concern for others. Community was consistent throughout most responses. All spoke of joining together to clear rubble and help their neighbors recover and rebuild. Interestingly, the schools became centers of physical care and emotional healing. Joseph remembered, "In cleaning up the school, teachers and students got closer together. That's part of what helped us get through." Another noted that teachers and students were able to wash their clothes at school. In one instance, the home economics teacher helped prepare food for teachers. Joseph recalled, "I spent quality time with my dad. He was joking that working and cleaning up was a way to build my muscles." Another remembered, "There was never an instance where somebody refused anyone else. We never had to decide who was going to eat or not eat."

We identified our fifth and final tier and theme as Esteem, Self-Respect, and Freedom. While no one welcomed the trauma, many felt they emerged stronger and paradoxically more independent and connected with their fellow islanders. All expressed gratitude for their survival. They noted their increased appreciation for their loved ones, their neighbors, their community, and their environment. We found their observations on transcendent spirituality especially insightful and moving.

One teacher reflected, "Spiritually, I just believe as long as you are alive, challenges will arise. The challenges you get make you stronger." Another noted, "People in the Virgin Islands have many different spiritualities ... Regardless of what we identify as, we are all neighbors." Julia summarized, "Life is short. You have to look for experiences that give you joy. Contribute and be helpful to people, especially children."

In addition to the modified hierarchy of needs that reflected our study's key themes, we searched for applications of the ethical codes of justice, critique, care, and community. Justice was reflected inversely in our participants' beliefs that they were denied benefits and attention accorded to mainland U.S. citizens. Critique was reflected in their sense of being recipients of discrimination as Islanders. Care was a dominant theme reflected in their concern for others. Community was consistent throughout most responses.

We believe these ethical codes worked symbiotically with our modified hierarchy of needs to help us gain a better understanding of our participants and their experiences. We also believe these insights helped us better understand the uniqueness of life experience in these American territories, along with our participants' sense of isolation as American citizens. Their feeling of community pride and resilience was palpable. The study raises questions about how the U.S. government might become more aware and supportive of the victims of such disasters. It also highlights the ways that educators respond to the basic needs of their students during significant disastrous events.

\section{SCHOLARLY SIGNIFICANCE}

In less than two decades, several natural disasters have ravaged U.S communities, wreaking physical and emotional devastation and destroying foliage, physical structures, and human lives. Sweeping tragedies have included Hurricane Michael and the Florida Panhandle in October 2018; California wildfires in November 2018; and Hurricane Katrina and the Gulf Coast in August 2005. Puerto Rico has suffered three devastating earthquakes between 2018 and the time of this writing. Whether the frequency 
and severity of these disasters is increasing is not the focus of this study. What is clear, however, is that natural disasters are not uncommon and have the potential to devastate communities, regardless of geographic location.

As we completed this writing, another type of natural disaster had affected the U.S. and world in ways previously unimagined by many. A pandemic paralyzed economies and disrupted schooling. News of virtual graduations, students competing courses online, and Advanced Placement courses disrupted created new anxieties among students, teachers, and parents. It may be appropriate for additional studies to apply the insights of this study to add the effects of an international pandemic on the ethics and perceptions of education stakeholders.

Such widespread catastrophes significantly affect fundamental community functions such as schooling. What is not well understood is how such destruction affects the individuals responsible for maintaining schools and schooling. Also unexplored is how educators apply their personal and professional values to practice their profession in the wake of traumatic personal challenges. While this study focused on the experiences of educators and former students during two specific hurricanes in U.S. Caribbean territories in 2017, the study provides insights into the ways educators in other disasters may respond to similar challenges. We believe our findings provide insights into ways that educators balance personal and professional values as they experience significant physical and emotional trauma following a natural disaster. These insights may be valuable to teacher educators as they train teachers and educational leaders to anticipate the effects of such catastrophes.

\section{REFERENCES}

Alvardo, C.B. (2017, September 17). Wrap-up of damages in P.R. caused by Hurricane Irma. Caribbean Business. https://caribbeanbusiness.com/wrap-up-of-damages-in-p-r-caused-by-hurricane-irma/

Bandura, A. (1971). Social Learning Theory. Retrieved from http://www.asecib.ase.ro/mps/Bandura_SocialLearningTheory.pdf

Bram, J. (2018, February 22). Puerto Rico and U.S. Virgin Islands after Hurricanes Irma and Maria. Federal Reserve Bank of New York.

Bridgman, T., Cummings, S., \& Ballard, J. (2019). Who built Maslow's Pyramid? A history of the creation of management studies' most famous symbol and its implications for management education. Academy of Management Learning \& Education, 18(1), 81-98. https://doi.org/10.5465/amle.2017.0351

Bruner, J. (1987). Life as narrative. Social Research, 54(1), 11-32.

Bruner, J. (2002). Making Stories: Law, Literature, Life. Cambridge, MA: Harvard University Press.

Chen, B., Van Assche, J., Vansteenkiste, M., Soenens, B., \& Beyers, W. (2015). Does psychological need satisfaction matter when environmental or financial safety are at risk? Journal of Happiness Studies, 16, 745-766.

Clandinin, D.J., \& Connelly, F.M. (2000). Narrative inquiry: Experience and story in qualitative research. San Francisco, CA: Jossey-Bass.

Dwyer, C. (2017, September 14). The Virgin Islands after Irma: It was like stepping onto another planet. National Public Radio.

Florida House of Representatives Select Committee on Hurricane Response and Preparedness. (2018, January 16). Final Report.

Furman, G.C. (2004). The ethic of community. Journal of Educational Administration, 42(2), 215-235. doi:10.1108/09578230410525612

Galea, S., Brewin, C.R., Jones, R.T., King, D.W., King, L.A., McNally, R.J., . . Kessler, R.C. (2007). Exposure to hurricane-related stressors and mental illness after Hurricane Katrina. Archives of General Psychiatry, 64(12), 1427-1434.

Koh, E. (2019, June 15). Students struggle with unrelenting stress as mental health care is elusive in the Panhandle eight months after Michael. The Miami Times/Herald Tallahassee Bureau. 
Lawrence-Lightfoot, S., \& Hoffman Davis, J. (1997). The art and science of portraiture. San Francisco, CA: Jossey-Bass

Lucario, L.H. (2018). Healing from complex trauma \& PTSD: A journey to healing from complex trauma. Retrieved from https://healingfromcomplextraumaandptsd.wordpress.com/category/hierarchy-ofneeds/

Madrid, P.A., \& Grant, R. (2008). Meeting mental health needs following a natural disaster: Lessons from Hurricane Katrina. Professional Psychology: Research and Practice, 39(1), 86-92. https://doi.org/10.1037/0735-7028.39.1.86

Martin, R. (2019, April 23). After two hurricanes, a floodgate of mental health issues in U.S. Virgin Islands. National Public Radio. Retrieved from https://www.npr.org/transcripts/716089187?storyId=716089187

Maslow, A.H. (1962). Toward a psychology of being. Princeton: D. Van Nostrand

Maslow, A.H. (1971). The farther reaches of human nature. New York, NY: The Viking Press.

Mccollum, S.A. (2018, February 16). A journey of action and excellence: When our students succeed, we all succeed! Post-Hurricane Irma and Hurricane Maria status report. Virgin Islands Department of Education.

McLeod, S. (2014). Maslow's hierarchy of needs. Simply Psychology. Retrieved from http://www.simplypsychology.org/maslow.html

Milken Institute School of Public Health. (2018). Project report: Ascertainment of the estimated excess mortality from Hurricane Maria in Puerto Rico. Milken Institute School of Public Health George Washington University in collaboration with the University of Puerto Rico Graduate School of Public Health. Retrieved from https://publichealth.gwu.edu/sites/default/files/downloads/projects/PRstudy/Acertainment\%20of $\% 20$ the $\% 20$ Estimated $\% 20$ Excess $\% 20$ Mortality\%20from $\% 20$ Hurricane $\% 20$ Maria $\% 20 \mathrm{in} \% 20$ Puer to\%20Rico.pdf

Perez-Pena, R. (2017, November 10). After Irma and Maria: How three spots on the U.S. Virgin Islands are faring. New York Times.

Peters, J.W. (2017, September 27). In the Virgin Islands, Hurricane Maria drowned what Irma didn't destroy. New York Times.

Reifels, L., Pietrantoni, L., Prati, G., Kim, Y., Kilpatrick, D., Dyb, G., . . O'Donnell, M. (2013). Lessons learned about psychosocial responses to disaster and mass trauma: an international perspective. European Journal of Psychotraumatology, 4(1), 17-34. doi: 10.3402/ejpt.v4i0.22897

Raphelson, S. (2017, November 14). Two months after Maria and Irma, U.S. Virgin Islands remain in the dark. National Public Radio.

Richardson, L. (2003). Writing: A method of inquiry. In N.K. Denzin \& Y. Lincoln (Eds.), Collecting and interpreting qualitative materials (pp. 499-541). Thousand Oaks, CA: Sage.

Riessman, C.K. (2008). Narrative analysis for the human sciences. Thousand Oaks, CA: Sage Publications, Inc.

Saldana, J. (2016). The coding manual for qualitative researchers ( $3^{\text {rd }}$ ed.). Thousand Oaks, CA: Sage

Saldana, J., \& Omasta, M. (2018). Qualitative research: Analyzing life. Thousand Oaks, CA. Sage.

Shapiro, J.P., \& Gross, S.J. (2013). Ethical educational leadership in turbulent times ( $2^{\text {nd }}$ ed.). New York, NY. Routledge.

Starratt, R.J. (2012). Cultivating an ethical school. New York: Routledge.

Storm Events Database (Report). (2017). National Climatic Data Center. Retrieved from https://www.ncdc.noaa.gov/

The New York Times. Hurricane Maria Live Updates: In Puerto Rico, the Storm "Destroyed Us". (2017, September 21). The New York Times. Retrieved from https://www.nytimes.com/2017/09/21/us/hurricane-maria-puerto-rico.html

U.S. Department of Agriculture. (2017). Recovery Following Hurricanes Irma \& Maria. U.S. Department of Agriculture Natural Resources Conservation Service Caribbean Area. Retrieved from https://www.nrcs.usda.gov/wps/portal/nrcs/detailfull/pr/home/?cid=nrcseprd1350825

54 Journal of Higher Education Theory and Practice Vol. 20(8) 2020 
U.S. Virgin Islands Department of Education. (2018). Retrieved from http://www.vide.vi/documents/public-relations/1422-post-hurricane-irma-and-hurricane-mariastatus-report-2-16-2018-1-1.html

U.S. Virgin Islands Housing Finance Authority. (2018, July 10). Community development block grant disaster recovery program action plan. Retrieved from https://www.facebook.com/VIHousingFinance/posts/1751424344905183

Yawson, D.O., Adu, M.O., Armah, F.A., Kusi, J., Ansah, I.G., \& Chiroro, C. (2015). A needs-based approach for exploring vulnerability and response to disaster risk in rural communities in low income countries. Second Integrated Research on Disaster Risk Conference, Beijing, China, June 7th- 9th, 2014. Australian Journal of Disaster \& Trauma Studies, 19, 27-36. Retrieved from http://search.ebscohost.com/login.aspx?direct=true\&AuthType $=$ shib\&db $=\mathrm{ccm} \& A N=109796470$ $\&$ site $=$ eds-live $\&$ scope $=$ site 